\title{
Cross-Sector Style Analysis Of Global Equities
}

Heng-Hsing Hsieh, PhD, CFA, University of the Western Cape, South Africa Kathleen Hodnett, PhD, University of the Western Cape, South Africa

\begin{abstract}
Value effect, size effect, mean reversal of long-term losers and the momentum of short-term winners are well-documented efficient market anomalies that exist in the cross-section of equity returns. Prior literature suggests that investing in stocks that have relatively higher beta, higher book-to-market ratio, lower market capitalization, higher prior 12-month returns and lower prior 36-month returns can reap above-average returns. Stocks possessing these investment styles are either riskier, or subject to investor overreaction. This paper undertakes to examine these anomalies across different sectors of the global equity market. The results of the univariate analysis show that market capitalization, book-to-market ratio and market beta are prominent factors that consistently explain the cross-section of global equity returns over the period from 01 January 1999 to 31 December 2009. Basic materials and oil and gas sector is the best performing sector while financials and technology sectors are the worst performing sectors on a risk-adjusted return basis over the examination period. Examination of the log cumulative style payoffs suggests that the value effect and mean reversals are particularly strong across sectors during turbulent times. The close resemblance of the cumulative payoffs to prior 12- and 36-month returns for the consumers goods and services and industrials sectors, as opposed to the widening gaps between the cumulative payoffs to prior 12- and 36-month returns for the technology sector, are possibly due to the relatively tighter competition and higher turnover rates for market leaders in the technology sector.
\end{abstract}

Keywords: Styles Anomalies; Value Effect; Size Effect; Mean Reversals; Momentum; Sector Analysis

\section{INTRODUCTION}

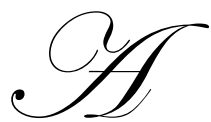

n investment style is defined by Kao and Shumaker (1999) as a system of classification by market segments that have distinguishing characteristics. Empirical anomalies relating to the capital asset pricing model (CAPM) such as the value effect of Basu (1977) and the size effect of Banz (1981) provide sources of potential investment styles for asset allocation purposes. Similarly, stocks from different sectors represent distinguishing segments in the cross-section of equities. Asset managers who allocate capital based on styles or sectors believe that market risk (measured by the beta coefficient) is not the only factor that explains the cross-section of equity returns, and hence above-market returns could be earned for overweighting or underweighting stocks belonging to particular style or sector categories.

Cavaglia and Morez (2002) indicate that increased integration in the global economy due to globalisation implies that sector allocation may be an effective method of exploring different dimensions of risk in the global equity market. Vardharah and Fabozzi (2007) further suggest that sector and style allocations are intercorrelated as sectors tend to tilt towards certain styles at times. It is the objective of this paper to identify prominent investment characteristics that consistently explain the cross-section of global equity returns, and to investigate the interrelationship of style allocation and sector allocation over the examination period. 


\section{LITERATURE REVIEW}

De Bondt and Thaler (1985) propose the overreaction hypothesis, suggesting that in making their investment decisions, irrational investors systematically overreact to the arrival of new information. Given that the fundamentals remain the same, the overstated or understated stock prices would be expected to correct to their longterm fundamental values. This phenomenon is commonly known as mean reversal. The overreaction hypothesis contradicts the weak-form efficient market hypothesis (EMH) of Fama $(1970,1991)$, which states that investors cannot outperform the market using historical price data which are already reflected in the current market price. Tests of the overreaction hypothesis by De Bondt and Thaler $(1985,1987)$ on the New York Stock Exchange (NYSE) indicate that investors could earn above-market returns by acquiring prior 36-month losers over the period from 1933 to 1982. Empirical literature supporting this contrarian strategy includes Chopra, Lakonishok and Ritter (1992) on the NYSE, Schiereck, De Bondt and Weber (1999) on the Frankfurt Stock Exchange (FSE), Page and Way (1992/1993) and Muller (1999) on the Johannesburg Stock Exchange (now the JSE Securities Exchange).

If investor overreaction is present in the equity market, momentum strategies that focus on acquiring past winners can be devised to profit from the temporary overshooting of asset prices before the market corrections/reversals take place. Studies conducted by Jegadeesh and Titman (1993) on the U.S. stock market reveal that abnormal returns are available for buying short-term winners based on prior 3- to 12-month prior returns. Similar results are obtained by Schiereck, De Bondt and Weber (1999) on the FSE, Chan, Hameed and Tong (2000) for international equity indices and Fraser and Page (2000) on the JSE.

The value and size effects, relating to the tests of the semi-strong form EMH, are the most prominent anomalies documented in empirical literature. The semi-strong form EMH states that investors cannot outperform the market using publicly available information contained in the company financial statements. The value effect refers to the phenomenon that value stocks with relatively lower price-to-fundamental ratios outperform growth stocks with relatively higher price-to-fundamental ratios. Basu (1977) finds that stocks with relatively lower priceto-earnings ratio outperform stocks with higher price-to-earnings ratio on the NYSE over the period from 1957 to 1971. The value effect is also supported by Lakonishok, Shleifer and Vishny (1994) on the NYSE using book valueto-market ratio, cash flow-to-price ratio, earnings yield and low historical sales growth as value indicators. On the other hand, Banz (1981) finds that firms with smaller market capitalization tend to earn higher returns than their large cap counterparts on the NYSE over the period from 1936 to 1975. Empirical literature also suggests that the documented value and size anomalies might be interrelated. Reinganum (1981) finds that the price-to-earnings ratio effect disappears when the size of the sample is controlled for, and hence suggests that size and value effects tend to relate to the same set of missing factors of the CAPM. Further research conducted by Reinganum (1983) indicates that abnormal returns earned by small firms tend to concentrate in January, which might be attributed to the January tax-loss selling effect.

Fama and French (1992) consolidate empirical findings on the value and size anomalies and test both anomalies jointly on the U.S. stock markets over the period from 1963 to 1990 . They find that book value-to-market ratio and market capitalization explain the cross-sectional equity returns over the examination period. Fama and French (1993) argue that value stocks and small firms are riskier, and investors demand higher returns to compensate these risks. They extend the CAPM of Sharpe (1964) and Lintner (1965) to incorporate value (proxied by book value-to-market ratio) and size (proxied by market capitalization) as risk factors in addition to the market risk premium of the CAPM (known as the Fama and French 3-factor model). They attempt to explain the returns on portfolios formed by documented anomalies such as the long-term price reversals of De Bondt and Thaler (1985), cash flow-to-price ratio, price-to-earnings ratio and historical sales growth of Lakonishok et al (1994) and the shortterm return momentum of Jegadeesh and Titman (1993) using the 3-factor model. Except for the momentum factor of Jegadeesh and Titman (1993), the 3-factor model adequately explains the returns of the portfolios formed by the attributes mentioned above. Fama and French (1996) argue that since these variables are all scaled versions of a firm's value, it is expected that the effects of some variables are subsumed by the more important variables. Extending the 3-factor model of Fama and French (1993) to incorporate an additional momentum factor proxied by prior 12-month returns, Carhart (1997) successfully explains the persistence in mutual funds' returns. International documentation of the value and size anomalies include Bekaert and Harvey (1995) and Claessens, Dasgupta and Glen (1998) on emerging economies, Fama and French (1998) on EAFE (Europe, Australia and the Far East) and 
the U.S. stock markets, Bauman, Conover and Miller (1998) on EAFE and the Canadian stock markets and Fraser and Page (2000), van Rensburg and Robertson (2003) and Rousseau and van Rensburg (2004) on the JSE.

Market anomalies are interpreted as an irrational behavioural phenomenon based on the overreaction hypothesis of De Bondt and Thaler (1985). On the other hand, Fama and French (1993) regard anomalies as missing risk factors of the CAPM. Regardless of whether the documented anomalies are the results of irrational trading behaviour or risks, Arnott, Hsu and Moore (2005) argue that the residuals of asset pricing models represent unnecessary noises that introduce unnecessary volatility without contributing to the fair valuation of stocks. In the presence of trading noise, a cap-weighted market proxy tends to incorporate more overvalued assets and less undervalued assets. This argument supports active portfolio management that attempts to place bets out-of-sync from broad market indices.

\section{DATA AND METHODOLOGY}

To explore sufficient global sector exposures, the Dow Jones (DJ) Sector Titans Composite is preferred as the research sample. This composite is comprised of the largest 30 international firms by market capitalization from each of the 19 second tier sectors of the Supersector structure defined by the Industry Classification Benchmark (ICB). This sample provides fair representation of major sectors from developed and emerging economies. Monthly historical prices, total returns, number of outstanding common stocks, market capitalization and per share book value of the 570 stocks comprising the DJ Sector Titans Composite over the period from 01 January 1996 to 31 December 2009 are obtained from DataStream International as of 01 March 2010. The historical prices, returns, market capitalizations and firm-specific attributes are converted and measured in U.S. dollar terms.

Due to the fact that DataStream International records data when the information is publicly available, the research database is not prune to look-ahead bias. Although survivorship bias is inherent in the database, the test results nevertheless provides insights to the payoff structures to style attributes of the most established firms representing their respective sectors. Stocks obtained from the 19 sectors are subdivided into 7 dominant categories, namely basic materials and oil and gas, consumer goods and services, banking and financials, healthcare, industrials, technology and telecommunications and utilities for cross-sector analysis. Details of sector categorization are presented in Table 1. Although the members of some sectors are more than others, the minimum number of 30 members should provide a good representation of the performance of each sector.

Table 1: Categorization and Acronyms for Sectors under Review

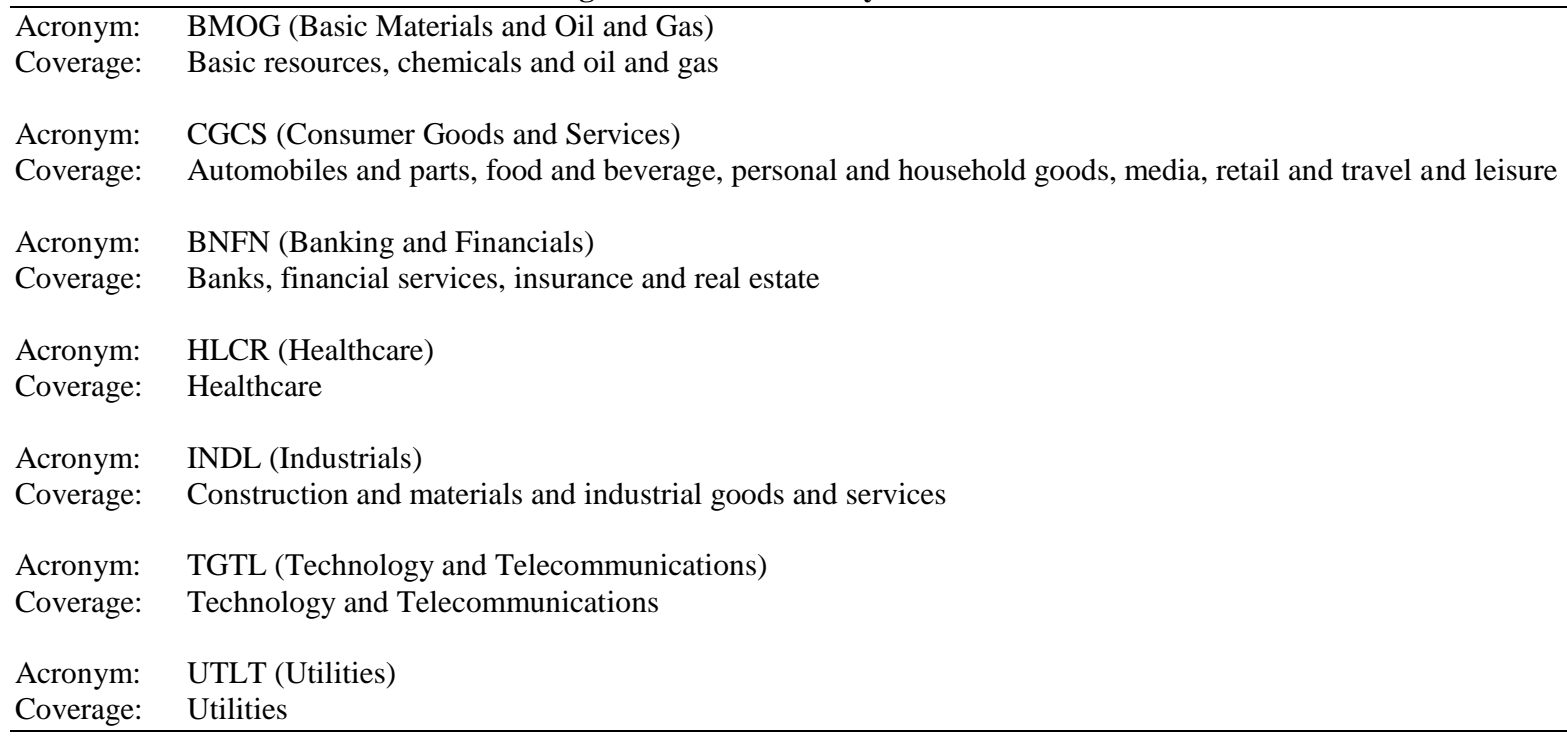


Style attributes whose monthly cross-sectional payoffs are examined include the beta coefficient (Beta), log of market capitalization (LSize), book value-to-market ratio (BVTM), prior 12-month total return (Mom12) and prior 36-month total return (Mom36). The detailed descriptions of these variables are presented in Table 2. To estimate the beta coefficient for sample stocks, a monthly-rebalanced market proxy is constructed by allocating equal weights to the 7 sector portfolios. The 7 monthly-rebalanced sector portfolios are constructed by allocating equal weights to constituent stocks in the respective sectors to avoid the capitalization bias mentioned in Arnott et al (2005). The choice of the equal-sector-weighted market proxy ensures fair representation of each sector in the proxy. On the other hand, the 3-month Treasury bill is employed as the risk-free proxy from a U.S. investor's perspective.

Table 2: Descriptions of Style Attributes

Beta: Using equal-sector-weighted sample of stocks as the market proxy and the U.S. 3-month Treasury bill as the risk-free proxy, beta is estimated by regressing prior 36-month excess stock returns on the prior 36-month market risk premium. This variable is computed monthly on a rolling basis over the examination period.

LSize: Logarithm of the current market capitalization of a common stock.

BVTM: Book value / current market capitalization of a common stock.

Mom12: Prior 12-month total return of a common stock. This variable is computed from the total return index (inclusive of capital gains and dividend yield).

Mom36: Prior 36-month total return of a common stock. This variable is computed from the total return index (inclusive of capital gains and dividend yield).

Since the first 36 months (01 January 1996 to 31 December 1998) of the research data is used to estimate the beta coefficient for sample stocks in the first monthly cross-section (see the description of beta in Table 2), the period from 01 January 1999 to 31 December 2009 is used as the examination period (a total of 132 months). The cross-section of each style attribute in each month of the examination period is winsorized first by restricting the observations in-between the $99.5^{\text {th }}$ percentile and the $0.5^{\text {th }}$ percentile to mitigate the influence of outliers. The monthly winsorized data for each style attribute is subsequently standardized into a normal distribution by subtracting each observation by the cross-sectional mean of the respective attribute and then dividing it by the crosssectional deviation of the respective attribute. Standardization enables meaningful comparison of the factor payoffs to various style attributes.

After the data in the sample is organized as discussed above, the univariate factor model similar to the cross-sectional regression of Fama and Macbeth (1973) is employed to determine the strength of each candidate style attribute in explaining the cross-section of equity returns as depicted in Equation 1, where $R_{i, S, t}$ is the realized total return on the $i$ th stock in sector $S$ for month $t ; F_{i, S, t-1}$ is the standardized value of the style attribute for the $i$ th stock in sector $S$ at the beginning of month $t$ (or style attribute for month $t-1$ ) and $i=1$ to total number of stocks in Sector $S$ for month $t$.

$$
R_{i, S, t}=a_{S, t}+b_{S, t} \times F_{i, S, t-1}+e_{i, S, t}
$$

The monthly regression coefficient, $b_{S, t}$ estimated by Equation 1 is the cross-sectional factor payoff to style attribute $F$ for sector $S$ in month $t$. Once the payoffs to all 5 style attributes for each of the 7 sectors (and the market proxy) are estimated for all the months in the examination period, the time-series means of monthly style (factor) payoffs are computed for each sector. The magnitudes of the $t$-statistics of the time-series mean style payoffs provide insight as to whether the respective style attributes consistently explain the cross-sectional equity returns over the examination period in each sector. Style payoffs in each sector are also examined over time by comparing the $\log$ cumulative monthly payoffs to the 5 factors in each sector. 
In an attempt to relate sector performance to distinctive sector style payoffs, risk and return performance statistics including annualized arithmetic returns, standard deviations and beta coefficients are estimated for each sector and the market proxy over the examination period. Risk-adjusted performance measures such as the Sharpe ratio, the Treynor measure and Jensen's alpha are also estimated for each sector and the market proxy. The Sharpe ratio for sector $X$ is the sector $X$ 's annualized arithmetic return, $R_{X, p . a .}$, in excess of the annualized arithmetic return on the risk-free proxy, USTB3M,p.a. (U.S. 3-month Treasury bill rate), divided by the annualized standard deviation for sector $X, \sigma_{x, p . a}$, as shown in Equation (2). The annualized standard deviation for sector $X, \sigma_{x, p . a .}$, is computed as the product of monthly sector standard deviation and the square root of $12, \sigma_{x, p . m .} \times \sqrt{12}$.

$$
\text { SharpeRatio }_{X \text { p.a. }}=\frac{R_{X \text { p.a. }}-U_{\text {STB3 }} M_{p . a .}}{\sigma_{X \text { p.a. }}}
$$

The Treynor measure and Jensen's alpha, on the other hand, employ the beta coefficient rather than the standard deviation as the measure of risk. The Beta coefficient of sector $X$ is estimated as the slope coefficient, $\beta_{X, m}$, by regressing the time-series excess return of sector $X, r_{X, t}-U S T B 3 M_{t}$, on the time-series excess return of the market proxy, $r_{m, t}-r f_{t}$, as shown in Equation 3, where $t=1$ to 132 (total number of months in the examination period). Jensen's alpha is represented by the intercept term of Equation 3, $\alpha_{X}$. Using the beta coefficient estimated from Equation 3, Treynor measure is estimated in Equation 4.

$$
\begin{gathered}
r_{X, t}-r f_{t}=\alpha_{X}+\beta_{X, m} \times\left(r_{m, t}-r f_{t}\right)+\varepsilon_{X, t} \\
\text { Treynor }_{X \text { p.a. }}=\frac{R_{X \text { p.a. }}-U S T B 3 M_{p . a .}}{\beta_{X, m .}}
\end{gathered}
$$

Observing the signs and statistical significance of mean style payoffs across sectors, in conjunction with the sectors' risk-adjusted performance over time, provides insights as to the distinctive dimension of style risks inherent in each sector over the examination period.

\section{EMPIRICAL FINDINGS}

The risk and return performance statistics across the 7 sectors and the equal-sector-weighted market proxy (ALL) are presented in Table 3. The basic materials and oil and gas sector (BMOG) has the highest annualized return $(25.7 \%)$ and total risk measured by standard deviation $(23.4 \%)$ over the examination period. On the other hand, the healthcare sector (HLCR) and the utility (UTLT) sector are characterized by low return (10.8\% and 10.7\% respectively) and low total risk (13.4\% and $14.5 \%$ respectively). The market proxy (ALL) has annualized return of $15.1 \%$ and standard deviation of $17.8 \%$. Using the Sharpe ratio as a measure of risk-adjusted performance, BMOG is the only sector that outperforms the sector-diversified market proxy (1.087 versus 0.832$)$. The banking and financial sector (BNFN) and the technology and telecommunications sector (TGTL) are the worst performing sectors with Sharpe ratio of 0.649 and 0.632 compared to the market proxy of 0.832 .

Taking into account the benefits of diversification, the systematic risk measured by the beta coefficient for BMOG (1.17) remains substantially higher than the market norm of 1.00. BNFN has the highest beta coefficient of 1.20 compared to substantially lower-than-average beta coefficients of 0.50 and 0.54 for HLCR and UTLT respectively. Examining the Treynor measure and Jensen's alpha across sectors, BMOG, HLCR, TGTL and UTLT outperform the market proxy in terms of the Treynor measure. However, BMBG is the only sector that has statistically significantly Jensen's alpha amongst other sectors. 
Table 3: Cross-Sector Performance Statistics

Panel A: Basic Performance Statistics

\begin{tabular}{lcccccccc}
\hline & BMOG & CGCS & BNFN & HLCR & INDL & TGTL & $\underline{\text { UTLT }}$ & $\underline{\text { ALL }}$ \\
Return: & $25.7 \%$ & $12.0 \%$ & $14.8 \%$ & $10.8 \%$ & $14.9 \%$ & $16.6 \%$ & $10.7 \%$ & $15.1 \%$ \\
Stdev: & $23.4 \%$ & $16.0 \%$ & $22.5 \%$ & $13.4 \%$ & $20.1 \%$ & $25.8 \%$ & $14.5 \%$ & $17.8 \%$ \\
Beta: & 1.17 & 0.87 & 1.20 & 0.50 & 1.07 & 1.09 & 0.54 & 1.00 \\
& & & & & & & & \\
Panel B: & Risk-Adjusted Performance Statistics & & & & & \\
\hline Sharpe: & 1.087 & 0.737 & 0.649 & 0.790 & 0.733 & 0.632 & 0.716 & 0.832 \\
Treynor: & 0.218 & 0.134 & 0.122 & 0.211 & 0.137 & 0.149 & 0.193 & 0.148 \\
Jensen: & 0.006 & -0.001 & -0.002 & 0.001 & -0.001 & 0.000 & 0.001 & 0.000 \\
t-Stats: & 2.043 & -1.504 & -1.258 & 0.540 & -0.678 & -0.010 & 0.314 & 0.000 \\
p-Value: & 0.043 & 0.135 & 0.211 & 0.590 & 0.499 & 0.992 & 0.754 & 1.000 \\
\hline
\end{tabular}

Sectors being analyzed include the basic materials and oil and gas (BMOG), consumer goods and services (CGCS), banking and financial (BNFN), healthcare (HLCR), industrials (INDL), technology and telecommunications (TGTL), utilities (UTLT) and the equal-sector-weighted market proxy (ALL). All measures are annualized with the exception of Jensen's alpha in Panel B.

Figure 1 through Figure 4 illustrates the log cumulative returns across sectors over the examination period. The log cumulative returns for the all-sector market proxy is highlighted in bold. BMOG and TGTL (refer to Figure 1) are the most distinctive sectors relative to the market performance. Although TGTL accumulated substantial returns in excess of the rest of the sectors in late 1990s, the sector lost all accumulated excess returns in the crash of the I.T. bubble in the early 2000s. BMOG, on the other hand, consistently accumulates excess returns over the examination period. INDL, CGCS, BNFN, HLCR and UTLT (Figure 2 through Figure 4) accumulate less returns compared to the equal-sector-weighted market proxy (ALL) over the examination period.

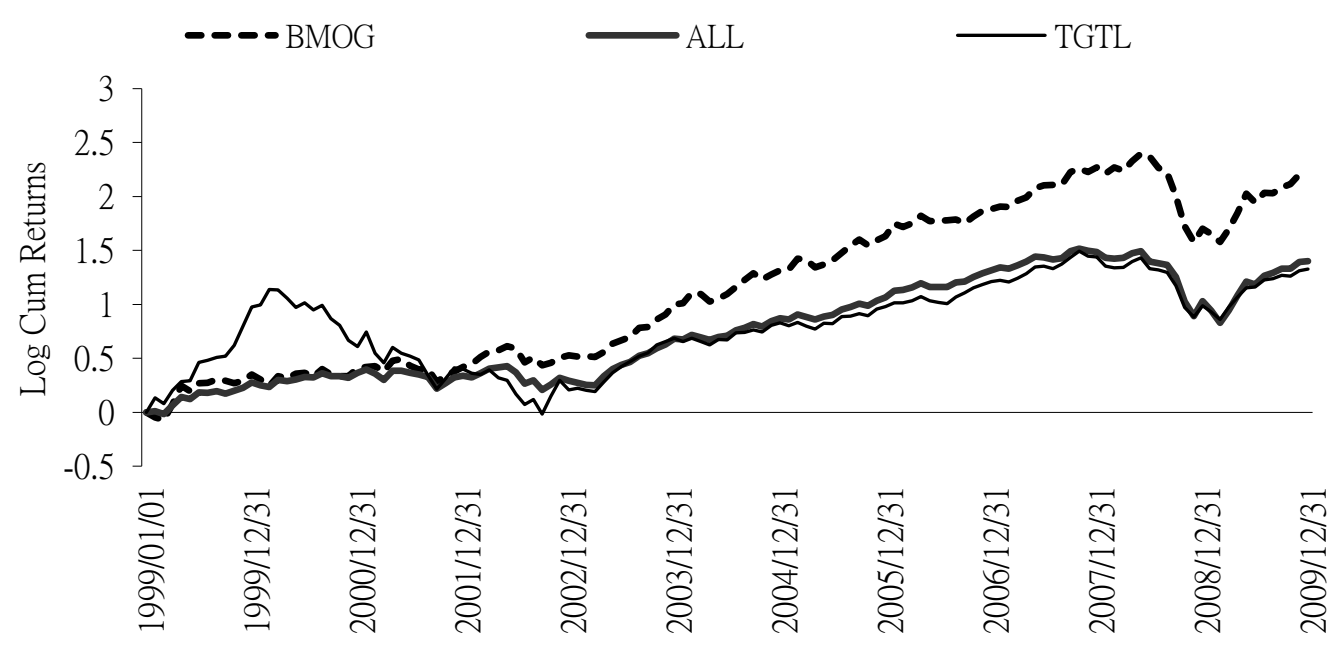

Figure 1: This figure displays the log cumulative returns for the basic materials and oil and gas sector (BMOG), the technology and telecommunications sector (TGTL) and the equal-sector-weighted market proxy (ALL) from 01 January 1999 to 31 December 2009. 


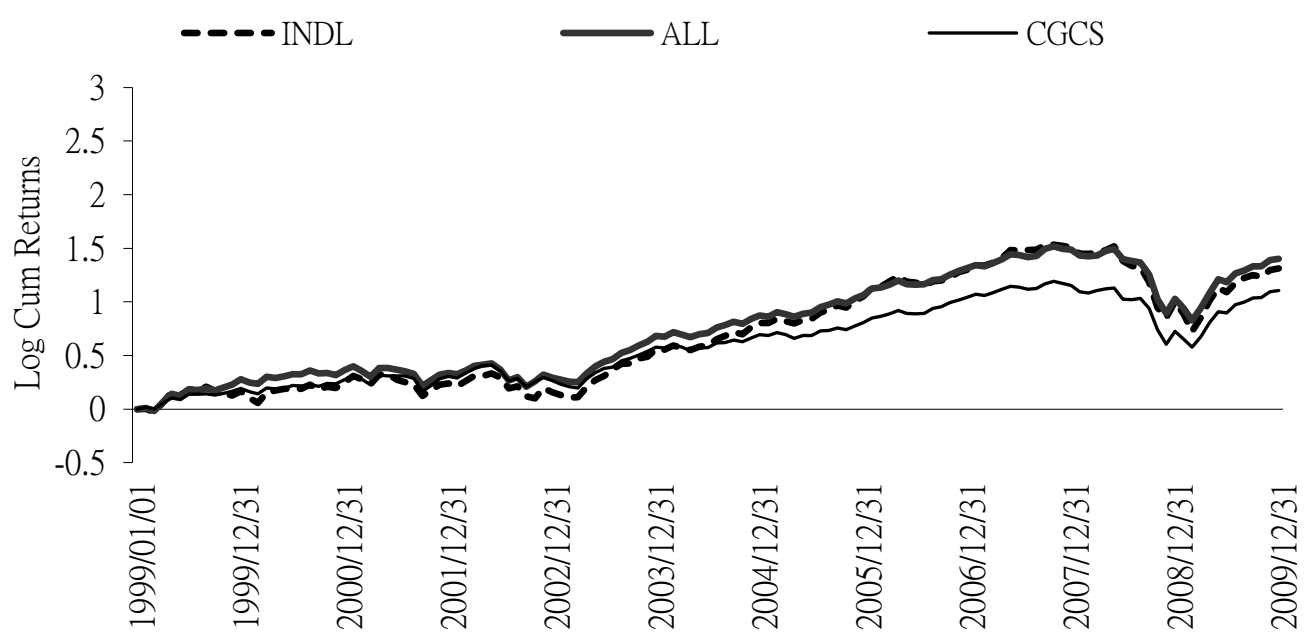

Figure 2: This figure displays the log cumulative returns for the industrials sector (INDL), the consumer goods and services sector (CGCS) and the equal-sector-weighted market proxy (ALL) from 01 January 1999 to 31 December 2009.

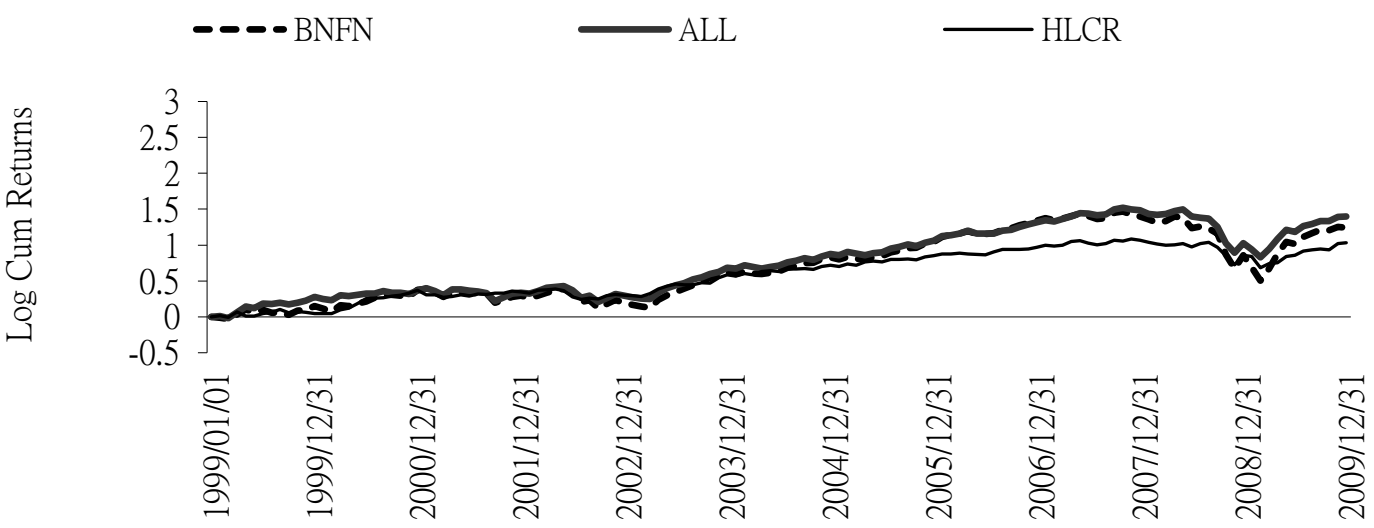

Figure 3: This figure displays the log cumulative returns for the banking and financial sector (BNFN), the healthcare sector (HLCR) and the equal-sector-weighted market proxy (ALL) from 01 January 1999 to 31 December 2009. 


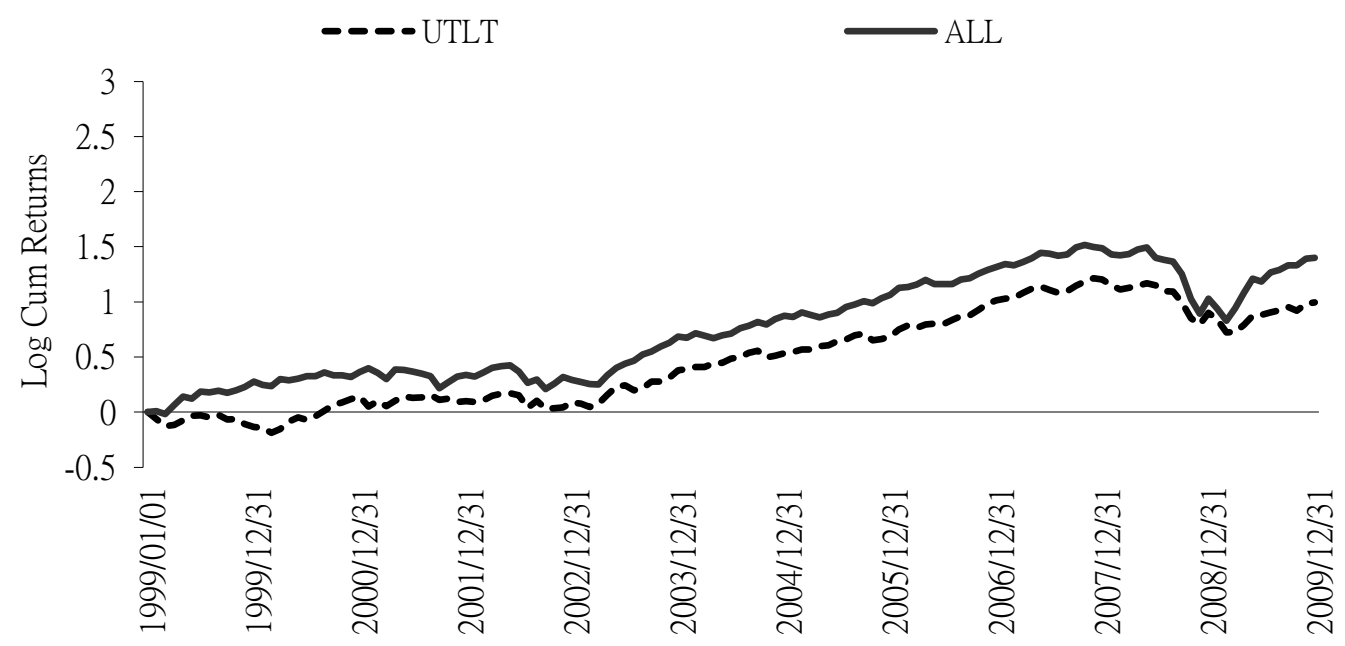

Figure 4: This figure displays the log cumulative returns for the utility sector (UTLT) and the equal-sector-weighted market proxy (ALL) from 01 January 1999 to 31 December 2009.

The mean style payoffs across sectors are presented in Table 4. While market risk (proxied by Beta), the value effect (proxied by BVTM) and the size effect (proxied by LSize) demonstrate their power in explaining crosssectional returns for most sectors, the short-term momentum effect (proxied by Mom12) and the long-term reversal effect (proxied by Mom36) are not significant across sectors.

Panel A: Beta

Table 4: Cross-Sector Mean Style Payoffs

\begin{tabular}{|c|c|c|c|c|c|c|c|c|}
\hline & $\underline{\mathrm{BMOG}}$ & CGCS & BNFN & $\underline{\text { HLCR }}$ & $\underline{\text { INDL }}$ & TGTL & UTLT & $\underline{\text { ALL }}$ \\
\hline Mean: & $\overline{0.005}$ & $\overline{0.004}$ & $\overline{0.003}$ & $\overline{0.007}$ & $\overline{0.003}$ & $\overline{0.006}$ & $\overline{0.001}$ & $\overline{0.004}$ \\
\hline t-Stats: & 1.938 & 1.719 & 1.115 & 2.337 & 0.979 & 2.669 & 0.265 & 1.813 \\
\hline p-Value: & 0.055 & 0.088 & 0.267 & 0.021 & 0.330 & 0.009 & 0.791 & 0.072 \\
\hline
\end{tabular}

Panel B: LSize (Log of Market Capitalization)

\begin{tabular}{lccccccccc}
\hline & BMOG & $\underline{\text { CGCS }}$ & $\underline{\text { BNFN }}$ & $\underline{\text { HLCR }}$ & $\underline{\text { INDL }}$ & $\underline{\text { TGTL }}$ & $\underline{\text { UTLT }}$ & $\underline{\text { ALL }}$ & -0.008 \\
Mean: & -0.008 & -0.008 & -0.008 & -0.008 & -0.007 & -0.010 & -0.008 & -0.008 \\
t-Stats: & -5.686 & -6.234 & -4.805 & -3.776 & -3.226 & -5.587 & -2.997 & -7.195 \\
p-Value: & 0.000 & 0.000 & 0.000 & 0.000 & 0.002 & 0.000 & 0.003 & 0.000
\end{tabular}

Panel C: BVTM (Book Value-to-Market Ratio)

\begin{tabular}{lllllllll}
\hline Mean: & $\underline{B M O G}$ & $\underline{\text { CGCS }}$ & $\underline{\text { BNFN }}$ & $\underline{\text { HLCR }}$ & $\underline{\text { INDL }}$ & $\underline{\text { TGTL }}$ & $\underline{\text { UTLT }}$ & $\underline{\text { ALL }}$ \\
t-Stats: & 4.386 & 0.005 & 0.006 & 0.005 & 0.006 & 0.004 & 0.003 & 0.006 \\
p-Value: & 0.000 & 0.000 & 0.003 & 0.082 & 0.001 & 0.042 & 0.111 & 0.000
\end{tabular}

Panel D: Mom12 (Prior 12-Month Returns)

\begin{tabular}{|c|c|c|c|c|c|c|c|c|}
\hline & BMOG & CGCS & BNFN & HLCR & INDL & TGTL & UTLT & ALL \\
\hline Mean: & $\overline{0.000}$ & $\overline{0.002}$ & $\overline{-0.001}$ & $\overline{0.003}$ & $\overline{-0.001}$ & $\overline{0.001}$ & $\overline{0.001}$ & $\overline{0.002}$ \\
\hline t-Stats: & 0.084 & 0.706 & -0.322 & 0.871 & -0.383 & 0.394 & 0.169 & 0.778 \\
\hline p-Value: & 0.933 & 0.481 & 0.748 & 0.385 & 0.703 & 0.695 & 0.866 & 0.438 \\
\hline \multicolumn{9}{|c|}{ Panel E:Mom36 (Prior 36-Month Returns) } \\
\hline & $\underline{\mathrm{BMOG}}$ & $\underline{\text { CGCS }}$ & BNFN & $\underline{\text { HLCR }}$ & $\underline{\mathrm{INDL}}$ & $\underline{\text { TGTL }}$ & $\underline{\mathrm{UTLT}}$ & $\underline{\mathrm{ALL}}$ \\
\hline Mean: & -0.002 & 0.000 & -0.004 & 0.000 & -0.003 & -0.005 & -0.006 & -0.001 \\
\hline t-Stats: & -0.663 & -0.238 & -1.336 & -0.029 & -1.113 & -2.031 & -1.337 & -0.426 \\
\hline p-Value: & 0.509 & 0.812 & 0.184 & 0.977 & 0.268 & 0.044 & 0.184 & 0.671 \\
\hline
\end{tabular}


The mean factor payoffs are computed from the monthly averages of the attribute coefficients for each sector using the Fama and Macbeth (1973) cross-sectional regressions over the period from 01 January 1999 to 31 December 2009. The attributes being analyzed include the beta coefficient (beta), log of market capitalization (LSize), book-value-to-market ratio (BVTM), prior 12-month returns (Mom12) and prior 36-month returns (Mom36).

Observing the signs of the mean style payoffs indicate that firms with relatively higher Beta, higher BVTM and lower LSize tend to earn relatively higher returns in all sectors under review. The importance of value and size risks in the Fama and French (1993) 3-factor model is assured by the fact that without the assistance from BVTM and LSize, Beta would not adequately explain the cross-section of equity returns for BNFN, INDL and UTLT.

The log cumulative style (factor) payoffs in each sector and the equal-sector-weighted market proxy are illustrated in Appendix Figure A1 through Appendix Figure A8. Observing the movements of style payoffs in each sector over time helps to detect the existence of specific timing (sign or magnitude changes) for the style payoffs examined in the respective sectors. Beta has a moderately positive effect on the cross-sectional equity returns over time across sectors. LSize is the most consistent phenomenon for all sectors over the examination period. BVTM, on the other hand, is particularly strong during turbulent times (early 2000s and 2008).

Although Mom12 and Mom36 seem to have weak influences on stock returns in Table 4 earlier, their payoffs are strong at times and in line with the business cycle across industries. The reversals (proxied by negative payoffs to Mom12 and Mom36) are particularly significant in economic turmoil (early 2000s and 2008) for most sectors. Overall, the effect of Mom36 on stock returns tend to be more negative compared to Mom12 in that the $\log$ cumulative payoffs to Mom36 are plotted below the payoffs to Mom12 for all sectors. The gap between cumulative payoffs to Mom12 and Mom36 widens substantially over time for TGTL (refer to Appendix Figure A6), which suggests that median-to-long-term winners are constantly replaced by short-term winners rapidly due to tight competition in the I.T. industry. In contrast, the gaps between cumulative payoffs to Mom12 and Mom36 for CGCS (refer to Appendix Figure A2) and INDL (refer to Appendix Figure A5) are substantially small compared to the rest of the sectors, which is indicative of the low turnover rates for winners in these two sectors.

\section{CONCLUSION}

BMOG is the best performing sector categorized by high risk and high return amongst other sectors over the examination period from 01 January 1999 to 31 December 2009. Although BMOG is the only sector with statistically significant alpha (with p-value just below 5\%), this intercept is expected to dissipate in Fama and French (1993) 3-factor model since the sector exhibits significant size and value payoffs. On the other hand, BNFN and TGTL are the worst performing sectors in terms of their Sharpe ratio, Treynor measure and Jensen's alpha. Although TGTL substantially outperformed the market in the late 1990s, the cumulative excess market returns subsequently dissipated during the crash of the I.T. bubble in the early 2000s. Beta, LSize and BVTM are found to be the prominent factors that explain the cross-sectional global equity returns. The positive effect of Beta and the negative effect of LSize on global equity returns are consistent over time across sectors. The positive value effect (proxied by BVTM) is stronger during turbulent times in the early 2000s and 2008. The reversal effect, proxied by the negative payoffs to Mom12 and Mom36, is found to be significant across sectors during turbulent times. Using changes in the magnitude between payoffs to Mom12 and Mom36 as indications for the turnover rate for sector winners, TGTL seems to exhibit tighter competition compared to CGCS and INDL over the examination period.

\section{ACKNOWLEDGEMENTS}

This work is supported by the National Research Foundation (NRF) of South Africa. We thank the research office of the University of the Western Cape for their support.

\section{NOTE}

1. This time-series regression is known as the capital asset pricing model (CAPM) of Sharpe (1964) and Lintner (1965). 


\section{AUTHOR INFORMATION}

Dr. Heng-Hsing Hsieh, CFA is currently a Senior Lecturer in the School of Business and Finance at the University of the Western Cape, South Africa. He is a CFA charterholder and a Registered Person on the JSE Securities Exchange (RPE). E-mail: ahsieh@uwc.ac.za. Corresponding Author.

Dr. Kathleen Hodnett is currently a Research Fellow (funded by the National Research Foundation (NRF) of South Africa) in the School of Business and Finance at the University of the Western Cape, South Africa.

\section{REFERENCES}

1. Arnott, R. D., Hsu, J. and Moore, P. (2005) 'Fundamental Indexation', Financial Analysts Journal, 61(2), 83-99.

2. Banz, R. W. (1981) 'The Relationship between Return and Market Value of Common Stocks', Journal of Financial Economics, 9, 3-18.

3. Basu, S. (1977) 'The Investment Performance of Common Stocks in Relation to Their Price to Earnings Ratio: A Test of the Efficient Markets Hypothesis', Journal of Finance, 32(3), 663-682.

4. Bauman, C., Conover, C. M. and Miller, R. E. (1998) 'Growth versus Value and Large-Cap versus SmallCap Stocks in International Markets', Financial Analysts Journal, 54(2), 75-89.

5. Bekaert, G. and Harvey, C. R. (1995) 'Time-Varying World Market Integration', Journal of Finance, 50(2), 401-444.

6. Carhart, M. M. (1997) 'On Persistence in Mutual Fund Performance', Journal of Finance, 52(1), 57-82.

7. Cavaglia, S. and Moroz, V. (2002) 'Cross-Industry, Cross-Country Allocation', Financial Analyst Journal, 58(6), 78-97.

8. Chan, K. C., Hameed, A. and Tong, W. (2000) 'Profitability of Momentum Strategies in the International Equity Markets', The Journal Financial and Quantitative Analysis, 35(2), 153-172.

9. Chopra, N., Lakonishok, J. and Ritter, J. R. (1992) 'Measuring Abnormal Performance - Do Stocks Overreact?', Journal of Financial Economics, 31, 235-268.

10. Claessens, S., Dasgupta, S. and Glen, J. (1998) 'The Cross-Section of Stock Returns: Evidence from Emerging Markets', Emerging Markets Quarterly, 12, 4-13.

11. De Bondt, W. F. M. and Thaler, R. H. (1985) 'Does the Stock Market Overreact?', Journal of Finance, 40(3), 793-805.

12. De Bondt, W. F. M. and Thaler, R. H. (1987) 'Further Evidence on Investor Overreaction and Stock Market Seasonality', Journal of Finance, 42(3), 557-581.

13. Fama, E. F. (1970) 'Efficient Capital Markets: A Review of Theory and Empirical Work', Journal of Finance, 25, 383-417.

14. Fama, E. F. (1991) 'Efficient Capital Markets: II’, Journal of Finance, vol(5), 1575-1617.

15. Fama, E. F. and French, K. R. (1992) 'The Cross-Section of Expected Stock Returns', Journal of Finance, 47, 427-465.

16. Fama, E. F. and French, K. R. (1993) 'Common Risk Factors in the Returns on Stocks and Bonds', Journal of Financial Economics, 33(1), 3-56.

17. Fama, E. F. and French, K. R. (1996) 'Multifactor Explanations of Asset Pricing Anomalies', Journal of Finance, 51(4), 55-84.

18. Fama, E. F. and French, K. R. (1998) 'Value Versus Growth: The International Evidence', Journal of Finance, 53(6), 1975-1999.

19. Fama, E. F. and MacBeth, J. (1973) 'Risk, Return, and Equilibrium', Journal of Political Economy, 81(3), 607-636.

20. Fraser, E. and Page, M. J. (2000) 'Value and Momentum Strategies: Evidence from the JSE', Investment Analysts Journal, 51, 25-35.

21. Hodnett K (2010), "Analysis of the Cross-Section of Equity Returns on the JSE Securities Exchange based on Linear and Nonlinear Modelling Techniques", Unpublished Doctoral Thesis, University of Cape Town.

22. Hsieh H (2010), "Applications of Global Equity Style Indices in Active and Passive Portfolio Management", Unpublished Doctoral Thesis, University of Cape Town 
23. Jegadeesh, N. and Titman, S. (1993) 'Returns to Buying Winners and Selling Losers: Implications for Stock Market Efficiency', Journal of Finance, 48(1), 65-91.

24. Kao, D. and Shumaker, R. D. (1999) 'Equity Style Timing', Financial Analysts Journal, 55(1), 37-47.

25. Lakonishok, J., Shleifer, A. and Vishny, R. W. (1994) 'Contrarian Investment, Extrapolation and Risk', Journal of Finance, 49(5), 1541-1578.

26. Muller, C. (1999), 'Investor Overreaction on the Johannesburg Stock Exchange', Investment Analysts Journal, 49, 5-17.

27. Page, M. J. and Way, C. V. (1992/1993) 'Stock Market Overreaction: The South African Evidence', Investment Analysts Journal, 36, 35-49.

28. Reinganum, M. R. (1981) 'Misspecification of Capital Asset Pricing - Empirical Anomalies Based on Earnings' Yields and Market Values', Journal of Financial Economics, 9, 19-46.

29. Reinganum, M. R. (1983) 'The Anomalous Stock Market Behavior of Small Firms in January - Empirical Tests for Tax-Loss Selling Effects', Journal of Financial Economics, 12, 89-104.

30. Schiereck, D., De Bondt, W. F. M. and Weber, M. (1999) 'Contrarian and Momentum Strategies in Germany', Financial Analysts Journal, 55(6), 104-116.

31. Sharpe, W. F. (1964) 'Capital Asset Prices: A Theory of Market Equilibrium Under Conditions of Risk', Journal of Finance, 19(3), 425-442.

32. Lintner, J. (1965) 'The Valuation of Risky Assets and the Selection of Risky Investments in Stock Portfolios and Capital Budgets', Review of Economics and Statistics, 47(1), 13-37.

33. Rousseau, R. and Van Rensburg, P. (2004) 'Time and the Payoff to Value Investing', Journal of Asset Management, 4(5), 318-325.

34. Van Rensburg, P. and Robertson, M. (2003) 'Size, Price-to-Earnings and Beta on the JSE', Investment Analysts Journal, 58, 1-11.

35. Vardharaj, R. and Fabozzi, F. J. (2007) 'Sector, Style, Region: Explaining Stock Allocation Performance', Financial Analysts Journal, 63(3), 59-70. 


\section{APPENDIX}

\section{LOG CUMULATIVE STYLE (FACTOR) PAYOFFS}

Log cumulative style (factor) payoffs are computed as the natural logarithm of the cumulative values of monthly attribute coefficients for each sector using the Fama and Macbeth (1973) cross-sectional regressions over the period from 01 January 1999 to 31 December 2009. The attributes being analyzed include beta coefficient (Beta), $\log$ of market capitalization (LSize), book-value-to-market ratio (BVTM), prior 12-month returns (Mom12) and prior 36month returns (Mom36).

\section{Basic Materials and Oil and Gas (BMOG)}

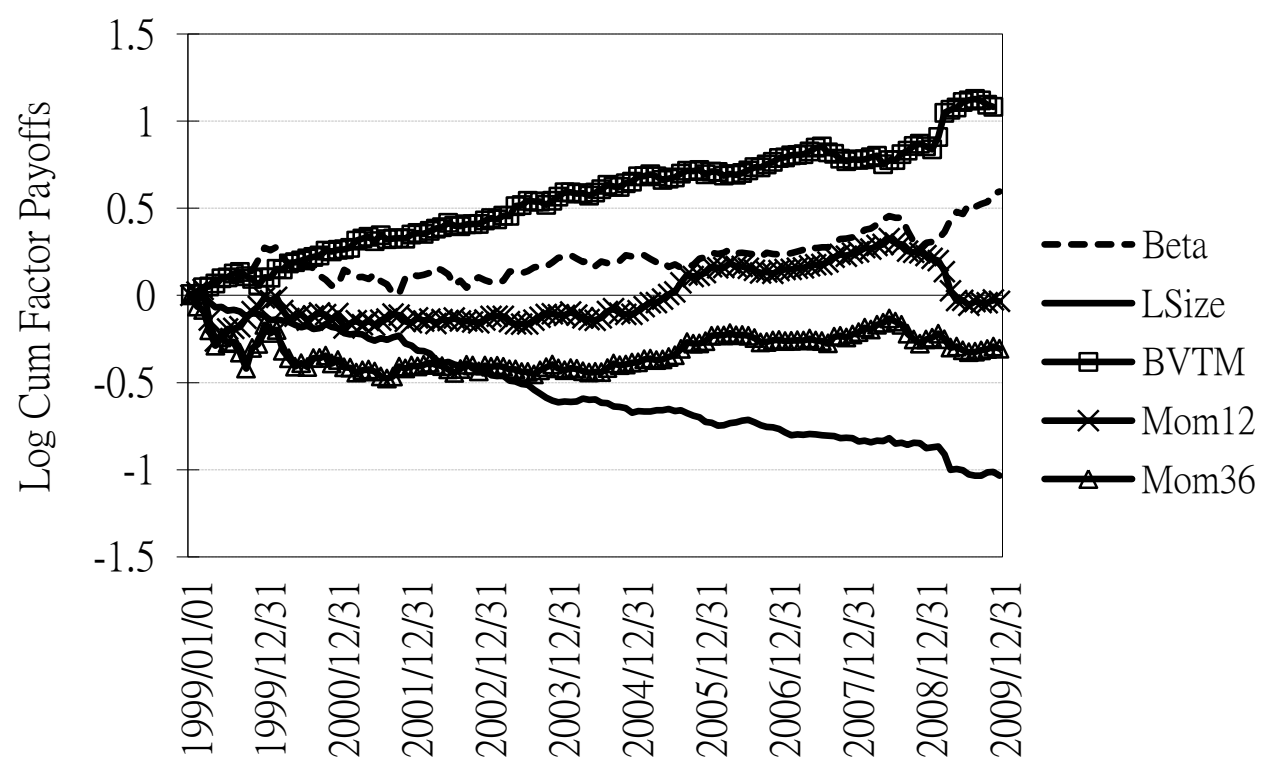

Figure A1: Log cumulative style payoffs for the basic materials and oil and gas sector (BMOG). This sector covers the basic resources, chemicals and oil and gas sectors from the second tier of the Supersector structure defined by the Industry Classification Benchmark (ICB). 


\section{Consumer Goods and Services (CGCS)}

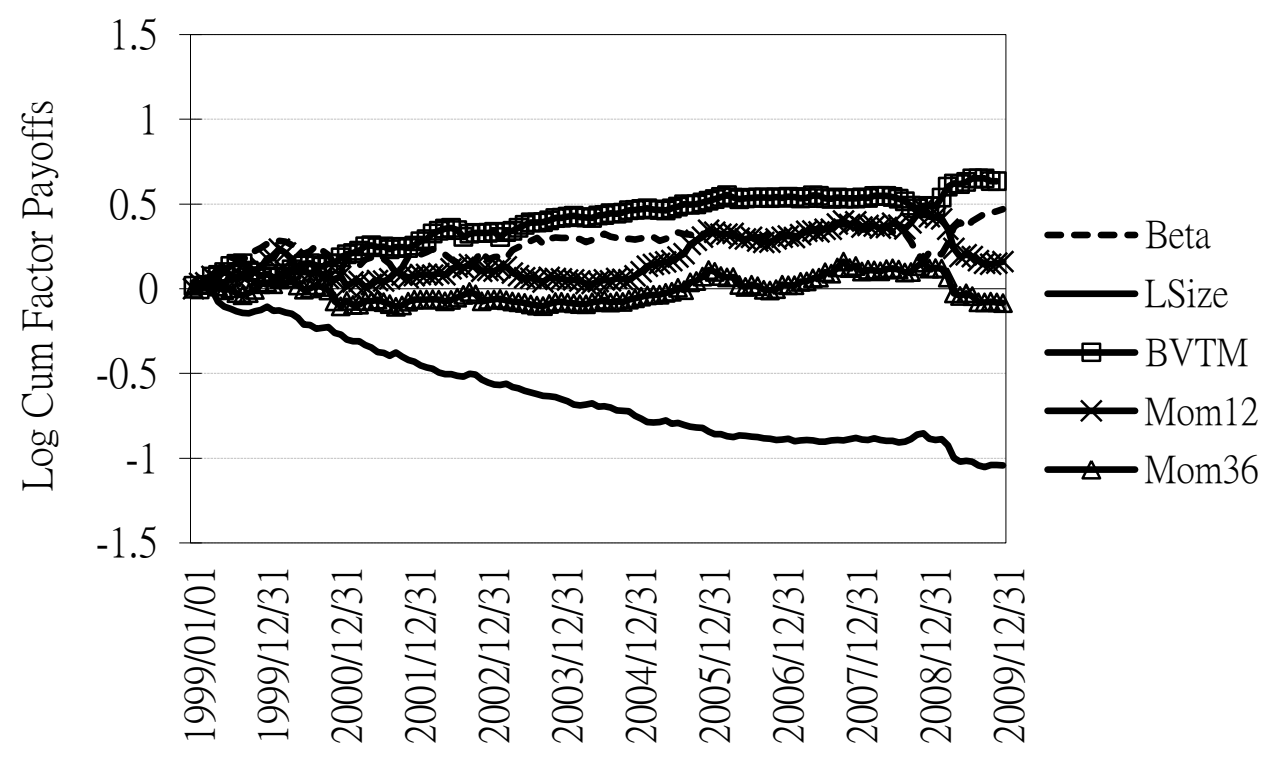

Figure A2: Log cumulative style payoffs for the consumer goods and services sector (CGCS) This sector covers the automobiles and parts, food and beverage, personal and household goods, media, retail and travel and leisure sectors from the second tier of the Supersector structure defined by the Industry Classification Benchmark (ICB).

\section{Banking and Financials (BNFN)}

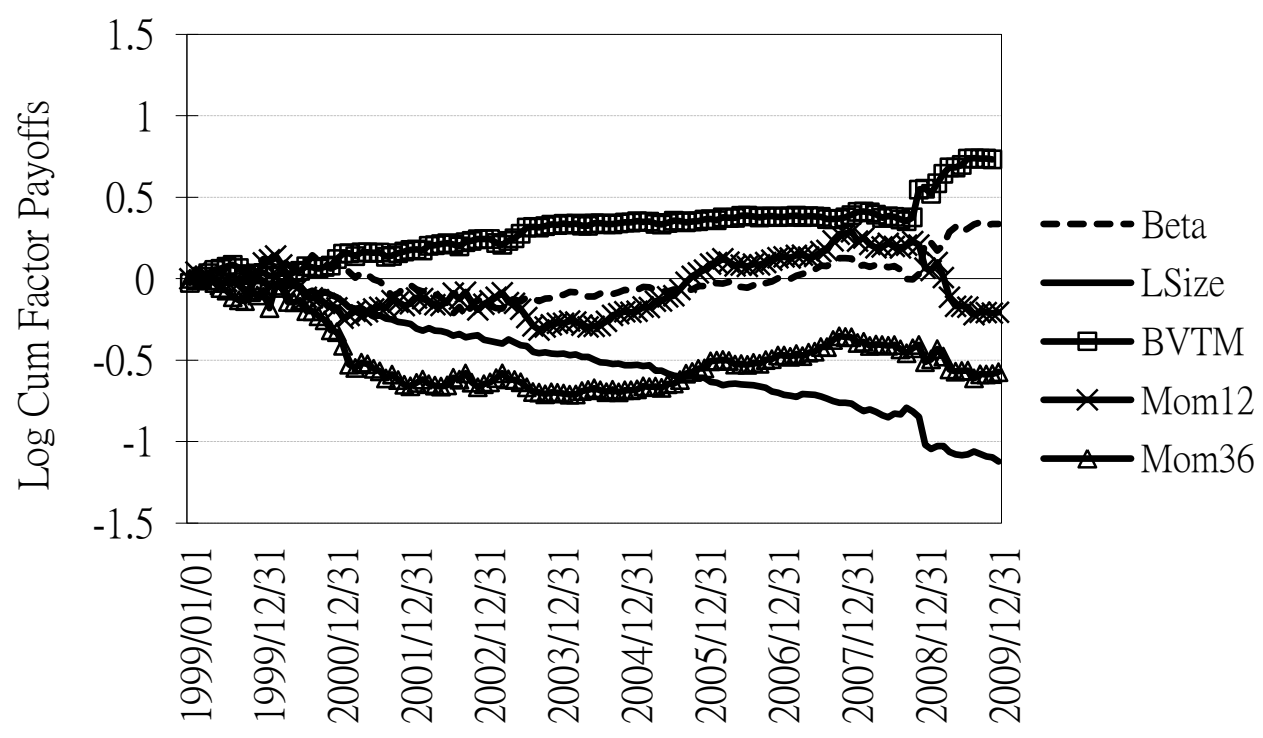

Figure A3: Log cumulative style payoffs for the banking and financial sector (BNFN). This sector covers banks, financial services, insurance and real estate sectors from the second tier of the Supersector structure defined by the Industry Classification Benchmark (ICB). 


\section{Healthcare (HLCR)}

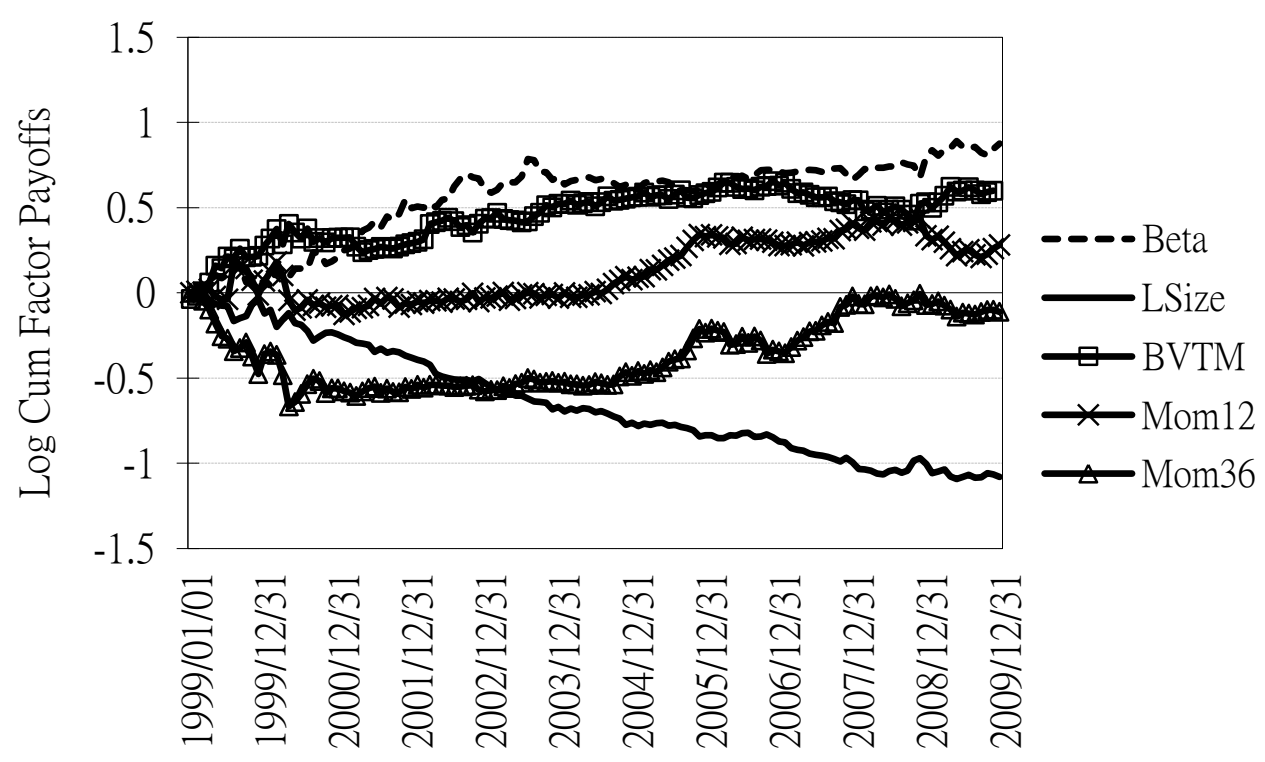

Figure A4: Log cumulative style payoffs for the healthcare sector (HLCR). This sector covers the healthcare sector from the second tier of the Supersector structure defined by the Industry Classification Benchmark (ICB).

\section{Industrials (INDL)}

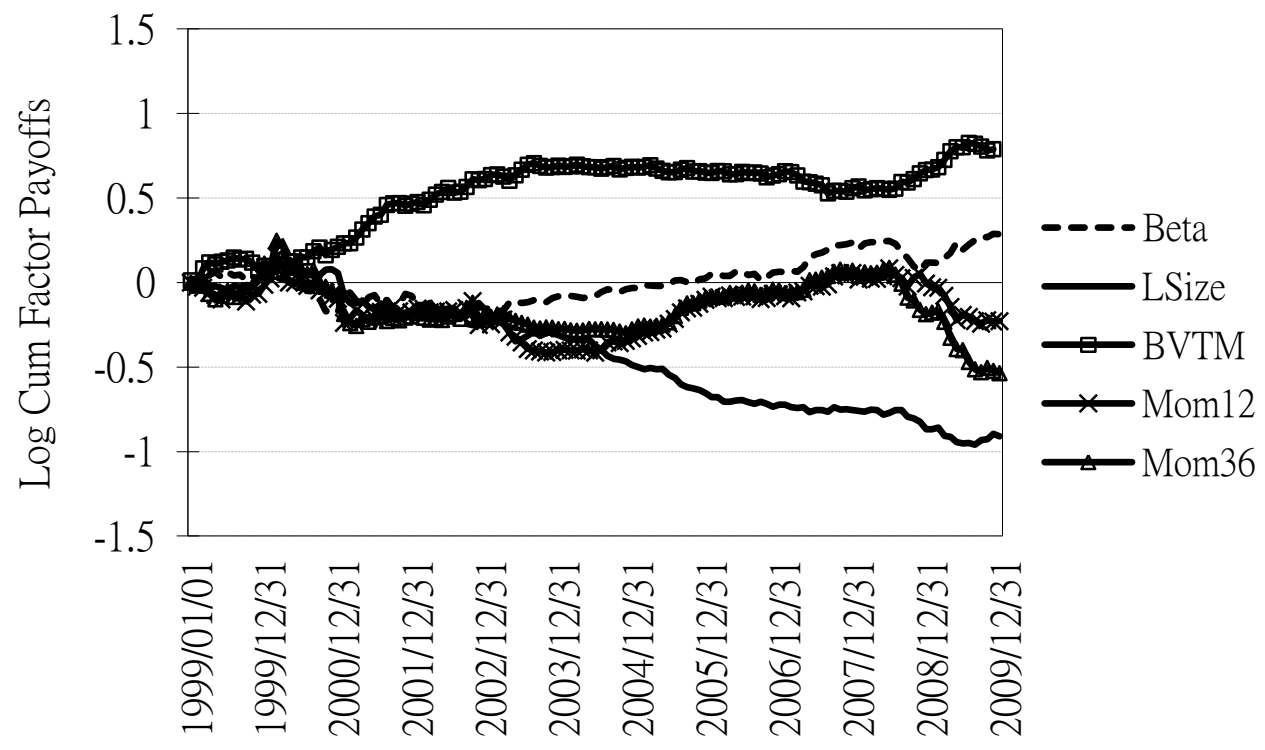

Figure A5: Log cumulative style payoffs for the industrials sector (INDL). This sector covers the construction and materials and industrial goods and services sectors from the second tier of the Supersector structure defined by the Industry Classification Benchmark (ICB). 


\section{Technology and Telecommunications (TGTL)}

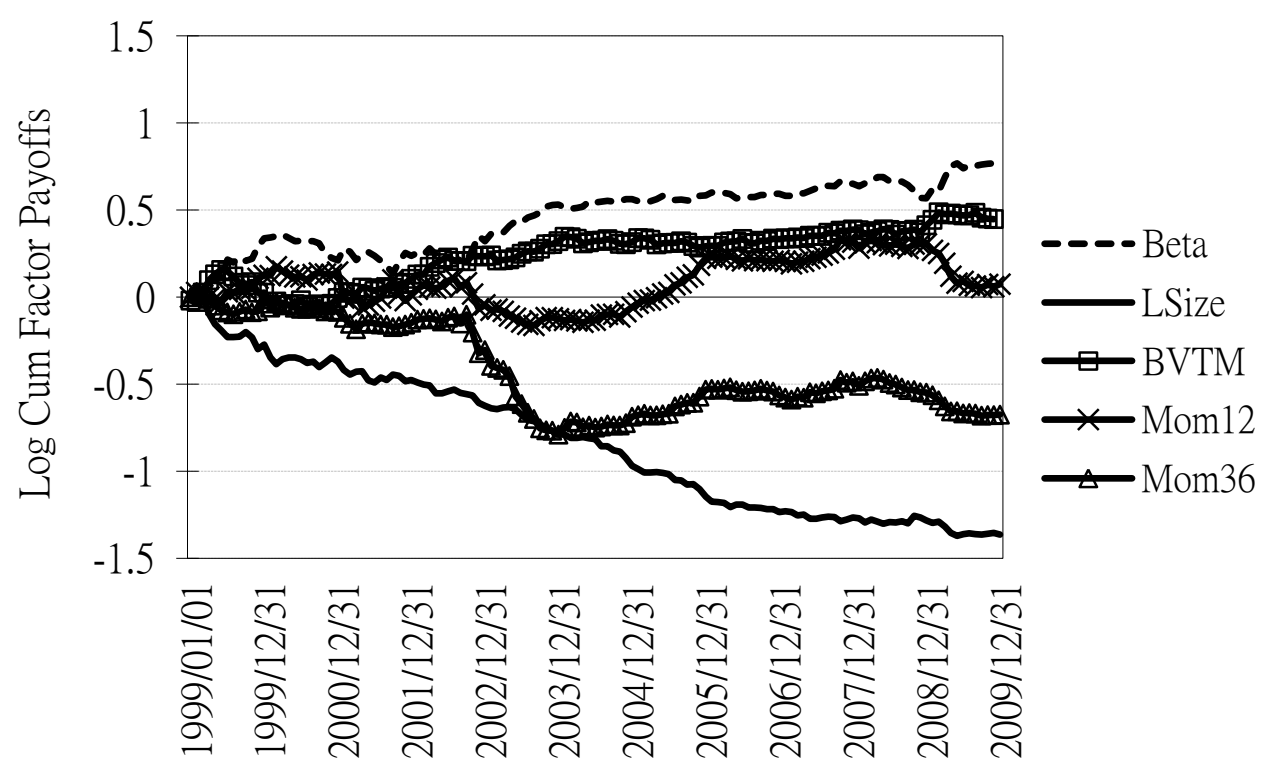

Figure A6: Log cumulative style payoffs for the technology and telecommunications sector (TGTL). This sector covers the technology and telecommunications sectors from the second tier of the Supersector structure defined by the Industry Classification Benchmark (ICB).

\section{Utilities (UTLT)}

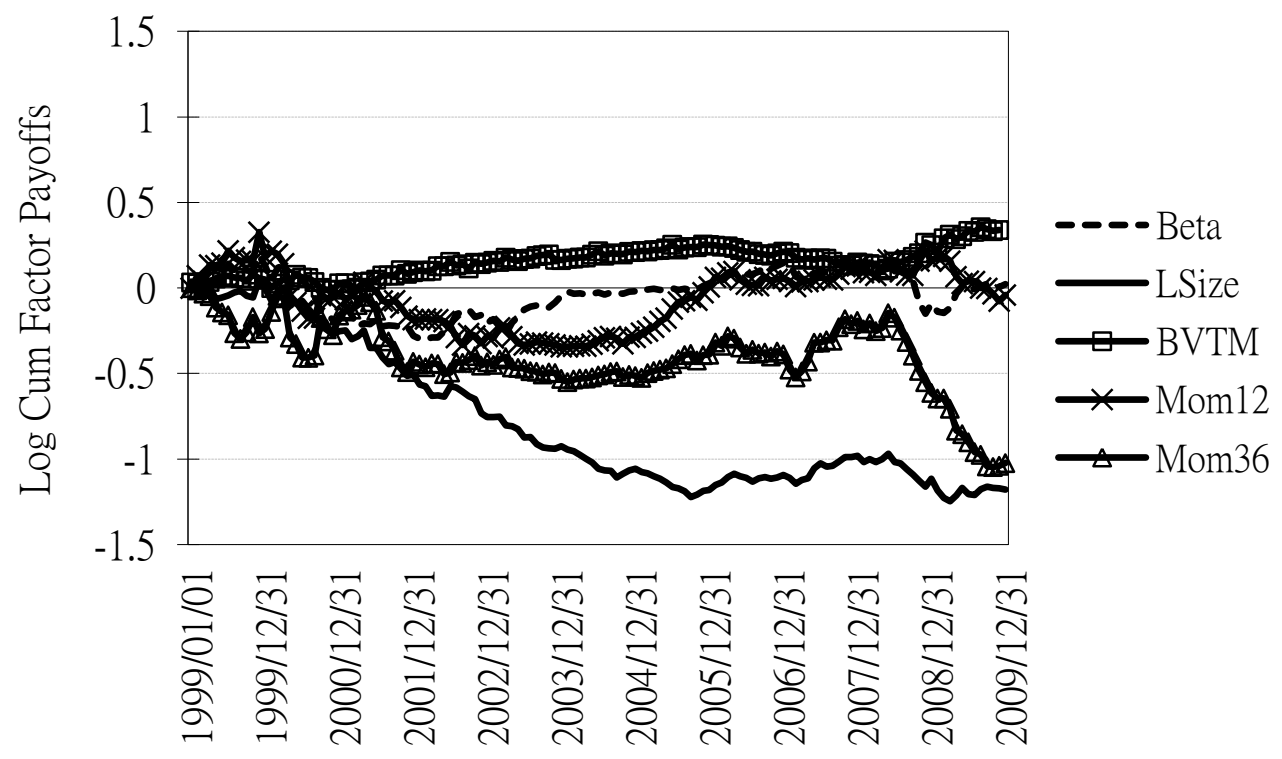

Figure A7: Log cumulative style payoffs for the utilities sector (UTLT). This sector covers the utilities sector from the second tier of the Supersector structure defined by the Industry Classification Benchmark (ICB). 


\section{Equal-Sector-Weighted Market Proxy (ALL)}

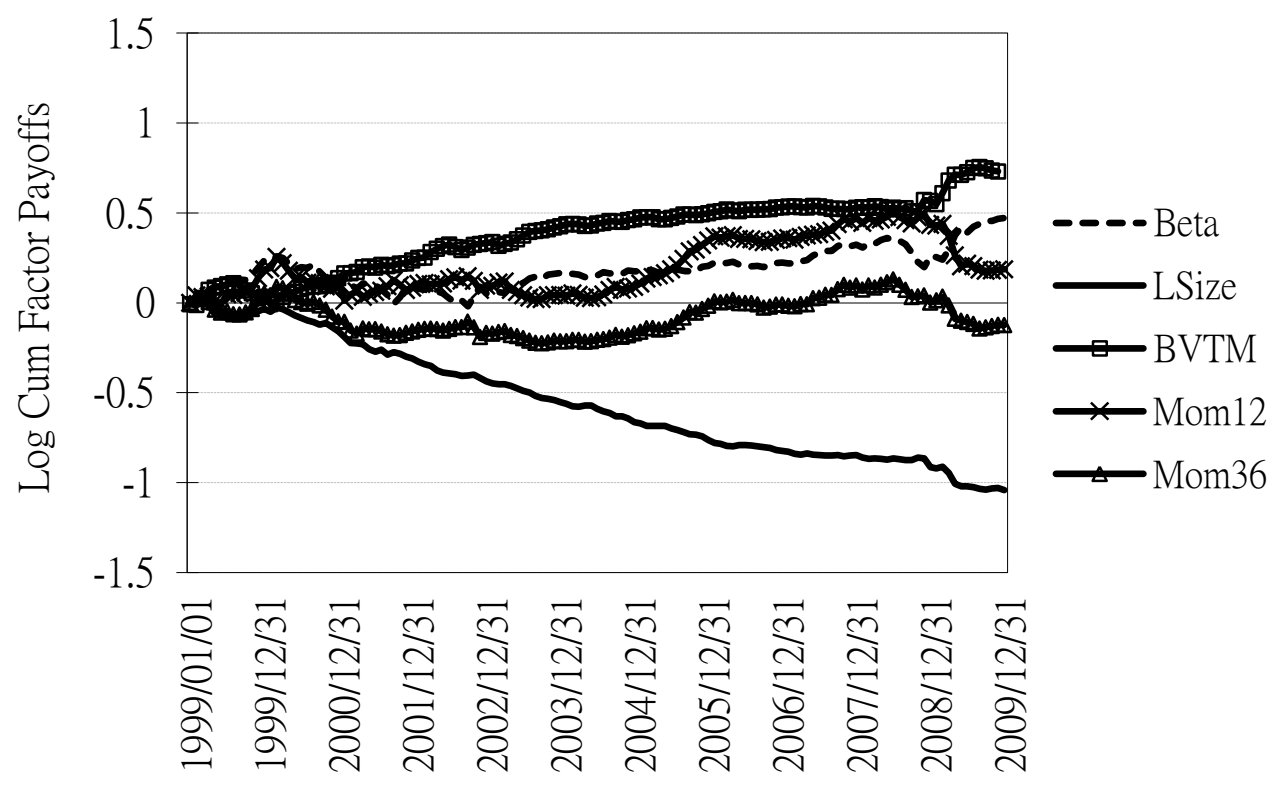

Figure A8: Log cumulative style payoffs for the equal-sector-weighted market proxy (ALL). Using the Dow Jones (DJ) Sector Titans Composite as the database, the market proxy is comprised of the 30 largest global firms by U.S. dollar market capitalization from each of the 19 second tier sectors of the Supersector structure defined by the Industry Classification Benchmark (ICB) as of 01 March 2010. The 19 sectors are reclassified into the basic materials and oil and gas sector, consumer goods and services sector, banking and financial sector, healthcare sector, industrials sector, technology and telecommunications sector and the utility sector. Equally-weighted sector benchmarks are subsequently constructed and rebalanced from these 7 sectors. The equal-sector-weighted market proxy represents a portfolio that allocate equal capital to each of these 7 sector benchmarks to ensure a fair sector representation in the market proxy and to avoid the cap-weighted drag discussed in Arnott $e t$ al (2005). 